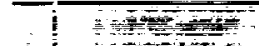 \\ $1 N-20$
NASA Technical
AIAA-94-2750
orandum 106519
2936
$18 P$ \\ Rocket Engine System Reliability Analyses Using Probabilistic and Fuzzy Logic Techniques
}

Terry L. Hardy

National Aeronautics and Space Administration

Lewis Research Center

Cleveland, Ohio

and

Douglas C. Rapp

Sverdrup Technology, Inc.

- Lewis Research Center Group

Brook Park, Ohio

Prepared for the

30th Joint Propulsion Conference

cosponsored by the AIAA, ASME, SAE, and ASEE

Indianapolis, Indiana, June 27-29, 1994

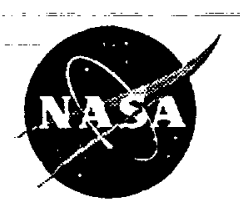

National Aeronautics and Space Administration
(NASA-TM-106519) ROCKET ENGINE

SYSTEM RELIABILITY ANALYSES USING

PROBABILISTIC AND FUZZY LOGIC

TECHNIQUES (NASA. Lewis Research

center) $18 \mathrm{p}$
$N 94-29403$

Unclas

$63 / 20$ 
a

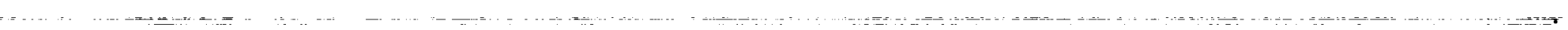




\title{
ROCKET ENGINE SYSTEM RELIABILITY ANALYSES USING PROBABILISTIC AND FUZZY LOGIC TECHNIQUES
}

\author{
Terry L. Hardy \\ National Aeronautics and Space Administration \\ Lewis Research Center \\ Cleveland, Ohio 44135 \\ Douglas C. Rapp \\ Sverdrup Technology, Inc. \\ Lewis Research Center Group \\ Brook Park, Ohio 44142
}

\begin{abstract}
The reliability of rocket engine systems was analyzed by using probabilistic and fuzzy logic techniques. Fault trees were developed for Integrated Modular Engine (IME) and Discrete engine systems, and then were used with the two techniques to quantify reliability. The IRRAS (Integrated Reliability and Risk Analysis System) computer code, developed for the U.S. Nuclear Regulatory Commission, was used for the probabilistic analyses, and FUZZYFTA (Fuzzy Fault Tree Analysis), a code developed at NASA Lewis Research Center, was used for the fuzzy logic analyses. Although both techniques provided estimates of the reliability of the IME and Discrete systems, probabilistic techniques emphasized uncertainty resulting from randomness in the system whereas fuzzy logic techniques emphasized uncertainty resulting from vagueness in the system. Because uncertainty can have both random and vague components, both techniques were found to be useful tools in the analysis of rocket engine system reliability.
\end{abstract}

\section{Introduction}

Reliability is a factor critical to the lifecycle cost of launch vehicles. Therefore, it is imperative that the reliability of all subsystems, including the rocket propulsion system, be improved if costs are to be reduced and the U.S. launch vehicle industry is to be competitive. The average success ratio of the current stable of United States launch vehicles is less than 95 percent; ${ }^{1}$ however, new programs are calling for launch vehicle reliabilities of 99.5 percent and greater. Achieving such high vehicle reliabilities requires quantitative predictive tools for assessing system risk. This is especially true for the propulsion system, which historically has been the reliability driver in space launch vehicles. ${ }^{1}$

In the current state of the art both qualitative and quantitative techniques are used to evaluate risk and reliability. One common technique is to use a fault tree analy- sis to perform a risk assessment of a system. A fault tree is a graphical model of the sequences of faults and failures that lead to an undesired event, such as the loss of a rocket engine. A fault tree can be evaluated quantitatively to estimate the reliability of a system. Such an evaluation is one of the core techniques in the probabilistic risk assessment of nuclear power plants. ${ }^{2}$ Fault trees are valuable for assessing large, complex systems because the pictorial display provides insight into the system, and the relative effects of contributing factors can be quantified.

To use fault tree analyses, we must have exact values for the probability of component failure. In most cases, however, these values are not known either because either no failure data exists, or because the existing data are vague or qualitative or were obtained under conditions different from those under which the hardware is being investigated. In the case of chemical rocket propulsion, little failure data exist. Probabilistic analyses are often used to analyze uncertainty due to randomness in the system. These techniques have been useful in assessing risk in the chemical, nuclear, and aerospace fields. ${ }^{3.4}$ However, probability theory requires that a single expected value be specified, all other values being deemed less probable. Probability theory then predicts the chances of achieving that expected value. In other words, probability theory requires that data have a statistical basis - a situation not often achievable in engineering analyses. Therefore, probabilistic analyses are not effective when only vague or qualitative data are available. Under conditions of vagueness, it may not be possible to select a single value that is most probable. Rather, only a range of possible values can be specified, all of which are equally likely. Recent studies have shown that fuzzy logic can be used to analyze many situations where the system description is vague or qualitative. 5 . In this study we developed a computer model that uses fuzzy logic nules to perform fault tree analyses. With this model we can calculate the reliability of rocket engine systems and compare our results to similar analyses done with conventional probabilistic approaches. 
For this study an Integrated Modular Engine system (IME) and a Discrete engine system were evaluated by using probabilistic and fuzzy logic techniques. These engine systems were previously analyzed, ${ }^{7}$ but uncertainty in the component failure probabilities was not addressed. This report discusses probabilistic and fuzzy logic approaches to evaluating rocket engine system reliability. Fault tree results from the probabilistic and fuzzy logic analyses of the IME and Discrete engine systems will also be provided for two different failure data bases. One data base contained data on the number of component failures per operating cycle and the other contained data on the number of failures per time period. Finally, this report discusses the differences in the results obtained with the two techniques, and offers recommendations for future work in this area.

\section{Rocket Engine System Description}

Two rocket engine designs were compared in this study. One design, known as the Discrete engine system design, has eight stand-alone engine units configured to provide vehicle thrust. In the Discrete design, if one component (such as a turbopump) fails, the corresponding thrust chamber must be shut down. An alternative design is the Integrated Modular Engine. In this design all the turbopump assemblies and thrust chamber assemblies are connected to common manifolds. In this system, therefore, a turbopump or thrust chamber could be shut down independently should a failure occur in either component. The IME design analyzed here has four turbopump assemblies and eight thrust chamber assemblies. Both the Discrete and the IME designs used an expander cycle configuration. A diagram of the Discrete engine system is shown in Fig. 1 and the RME system is shown in Fig. 2. These designs are described in more detail in references 7-9.

\section{Eault Tree Analysis Techniques}

A fault tree is a top-down method for quantifying reliability on the basis of recognized system failures. A major system failure is identified as the top event, and the branches of the fault tree represent system conditions that may lead to system failure. A system condition can be classified either as an individual component failure or a degraded component performance state that may, alone or in some combination with other system conditions, cause the undesired top event to occur. Component failures are considered in this report; degraded component operational states are not.

The rate at which system components fail may be statistically characterized by their observed occurrence. The failures observed may be categorized as demand-based or time-based. Those failures that occur during a system operating period (cycles, firings) are termed demand-based, and those that occur per unit system operating time (seconds, hours) are termed timebased. Both demand-based and time-based data bases were available for the analyses reported here. ${ }^{7,10}$ Because the component failure probabilities differed greatly in these data bases, both were used for these analyses of the rocket engine systems. The failure probabilities that were demand-based could be used in the fault tree analyses without further mathematical manipulation. However, the failure rates that were time-based were converted to failure probabilities by using the equation

$$
P=1-\exp (-\lambda t)
$$

where $P$ is the failure probability, $\lambda$ is the time-based failure rate, and $t$ is the operation time, which was assumed to be $400 \mathrm{~s}$ for the analyses conducted here.

The probabilistic and fuzzy logic techniques used in this study to analyze the fault trees for the IME and Discrete systems are described in the following sections.

\section{Probabilistic Technique}

It is difficult to accurately quantify the failure rate of rocket engine components because of numerous factors. Two factors that contribute to this difficulty are the relatively low number of observed failures and a paucity of historical data. To grasp the uncertainty in absolute failure rates, we must construct probability distributions that encompass the mean value of observed demandbased and time-based failures.

Probability distributions describe a component's failure rate in terms of the mean and the variance of observed or estimated values. From these we can predict, with various levels of confidence, the probability of a specific failure rate for a component. For instance, with a normal distribution, as in Fig. 3, the probability that the true failure rate is greater than its mean value is 0.5 (i.e. 50 percent). Confidence intervals may be established by bounding the distribution by lower and upper confidence limits. For example, a 90-percent confidence interval about the mean value in a normal distribution will have confidence limits at the 5-and 95-percent probability levels. Thus, 90-percent confidence exists that the true failure rate lies within these limits. Many forms of probability distributions have been employed in modeling the reliability of mechanical equipment; in this report, we use the normal and lognormal distributions ${ }^{11}$ with a 20percent coefficient of variation( $\mathrm{CoV})$, which means that the standard deviation is \pm 20 percent of the mean.

Probabilistic estimates of Discrete and Integrated Modular Engine system failure rates were obtained by using IRRAS (Integrated Reliability and Risk Analysis System, Version 4.0), which was developed for the U.S. Nuclear Regulatory Commission to do probabilistic risk 
assessments. ${ }^{12}$ Component failure rate data ${ }^{7,10}$ and variability information were input separately into the software. For the demand-based data base, the probability of failure of a component was input directly. For the timebased data base, the time-based failure probability equation given previously was used to calculate the probability of component failure. Each component failure probability was then combined with fault tree failure logic to generate minimal cut sets.

A minimal cut set is the smallest combination of component failures (basic events) that must occur to cause the top event to occur. ${ }^{13}$ Here, the top event is defined as failure of the IME or the Discrete system to provide the required thrust. This top event is caused by the failure of more than one redundant component (such as turbopumps) or a single-point failure (such as the loss of a manifold). A highly reliable system is one that has a minimal number of cut sets, a maximum number of component failures within a cut set, and a minimal failure probability of all components. Hence, the number of branches that can initiate failure of the top event are minimized and each branch is unlikely to occur. The probability of overall system failure, or point estimate, is subsequently determined from the individual minimal cut set failure probabilities on the basis of the mean values of the component failure rates, without consideration for uncertainty. ${ }^{12}$

The Discrete engine system had 112 components and 3388 minimal cut sets. All of the Discrete system cut sets were composed of two basic events. The IME system consisted of 122 components and 2098 minimal cut sets. Six of the IME minimal cut sets were single-point failures (manifolds, sensors); that is, only one component failure was required for the top event to occur. The remaining 2092 minimal cut sets were composed of 2 components. The difference in the number of cut sets for the two systems was the result of differences in system integration.

Like the component failure probabilities, the top event failure probability value has an associated uncertainty. The magnitude of this uncertainty depends on many factors, including the number of components, the component failure probability distributions, and the fault tree failure logic. Uncertainty analyses were conducted with the IRRAS code using a Monte Carlo random sampling technique. This is a technique in which the system fault tree is repeatedly analyzed on the basis of a sampling from each component failure probability distribution. The results were assumed to represent the true failure state of the system. The IRRAS code reports the first four central moments of system failure probability distributions: the mean, the variance (reported as standard deviation), the skewness (symmetry, reported as coefficient of) and the kurtosis (peakedness, reported as coefficient of). The coefficients of skewness and kurtosis equal to 0 and 3 , respectively, were representative of a normal distribution.

Each component's relative contribution to the overall probability of system failure was measured with a dimensionless importance factor, called the FussellVesely (F-V) importance measure ${ }^{12}$ within the IRRAS software. The F-V importance measure indicates the percentage contributed to the overall probability of system failure by the cut sets containing the component. Thus, the F-V importance measure can be used to identify critical components for reliability enhancement. Obviously, low F-V values are desirable.

\section{Euzzy Logic Technique}

The key concept in fuzzy logic is that of the fuzzy set, developed by Lotfi Zadeh in $1965 .{ }^{14}$ Fuzzy set theory recognizes that there are certain sets which have imprecise boundaries. An example of such a set is the set of tall people, where tall is a vague or fuzzy term. The imprecision in the boundary is quantified by what is known as a membership function. This membership function represents numerically the degree to which an element is the member of the set. For instance, someone who is $5 \mathrm{ft} 6$ in tall may be assigned a value of 0.5 for the membership function of the set of tall people (this person could be described as being somewhat tall), whereas someone $7 \mathrm{ft}$ tall would have a value of 1 for the membership function (very tall). Thus the person who is $5 \mathrm{ft} 6$ in tall is partially a member of the set of tall people, whereas the person who is $7 \mathrm{ft}$ tall is completely a member of this set. The fuzzy, or multivalent, set has a gradual transition between membership and nonmembership. Contrast this with the classical set where a sharp division exists between membership and nonmembership. If we use $6 \mathrm{ft}$ as the discriminating value, in a classical, or bivalent, set everyone whose height is over $6 \mathrm{ft}$ would be tall (membership function $=1$ ), while everyone whose height is less than $6 \mathrm{ft}$ would not be a member of the set (membership function $=0$ ). Figure 4 compares the classical set and the fuzzy set of tall people.

Because the fuzzy set allows for various grades of membership, the concept is well-suited for use in reliability analyses. In many such analyses the system reliability is difficult to evaluate because the failure probabilities of components are not known, the environment changes from one system to another, or the only data available are either vague or qualitative. To evaluate such situations we can use a fuzzy set defined over the failure probability space. Often a trapezoid is employed to represent the failure probability range of a component, as shown in Fig. 5. This figure can be interpreted as showing a failure probability is around 0.5 , but it could be as low as 0.25 or as high as 0.75 . Experts may provide such a 
description when asked to evaluate the reliability of a particular component.

Once the fuzzy sets have been determined for each component in the system, a fault tree analysis can be performed to obtain the overall system reliability. The FUZZYFTA (Fuzzy Logic Fault Tree Analysis) code was developed at NASA Lewis Research Center. It uses fuzzy logic to obtain the probability of an undesirable event. The FUZZYFTA code user provides the fuzzy sets that describe the component failure probabilities (basic events). These component fuzzy sets are derived from expert opinion or reliability data bases available to the user. In addition, the user supplies the logical relationships (AND, OR gates) between the top event and the basic events. The output from the code is a fuzzy set for the probability range of the top event and a point estimate of the failure probability. In addition, the code supplies importance factors similar to those obtained by using the Fussell-Vesely technique for probabilistic analyses. These importance factors indicate which components are the major contributors to the probability of system failure; they are calculated by setting each component's failure probability equal to zero and then calculating the difference between the new system failure probability range and the baseline failure probability range.

The FUZZYFTA model uses the extension principle to compute the probability of failure for the top event (system) on the basis of the component failure fuzzy sets. The extension principle is a general methodology for extending operations in classical mathematics to their equivalents by using fuzzy sets, as described in references 15 and 16 . The mathematical relations used in FUZZYFTA are summarized in Table 1. The relations for AND and OR gates were obtained from reference 16. And as part of this study, we derived the fuzzy logic relation for the N/M gate (N events out of a total of $M$ inputs must occur for the gate event to occur) from approximations in the literature. ${ }^{12,16}$ Unlike the probabilistic analysis, the FUZZYFTA code does not use Monte Carlo sampling to obtain the fuzzy set for the top event. Rather, the code obtains the range of possible failure rates for the top event by using the relations in Table 1 to directly manipulate the four comer points of the trapezoidal fuzzy sets.

For the demand-based fuzzy fault tree analyses in this study, the fuzzy sets representing the component failure probabilities were obtained by assuming that the extreme values of the trapezoidal fuzzy set were \pm 20 percent of the mean values used in the probabilistic analysis previously described. The interior values of the fuzzy set were assumed to be halfway between the mean and the extreme values. For example, if the mean value of a valve failure probability was 0.0002 , then the fuzzy set for a range of \pm 20 percent could be described by a trapezoid over the probability range $\left(q_{1}=0.00016, p_{1}=0.00018\right.$,
$\mathrm{p}_{\mathrm{T}}=0.00022$, and $\left.\mathrm{q}_{\mathrm{r}}=0.00024\right)$ with corresponding membership function values of $(0,1,1$, and 0$)$. For this case, then, the probability of failure for the valve is most likely between 0.00018 and 0.00022 , but could be as high as 0.00024 or as low as 0.00016 .

\section{Results}

We used both probabilistic and fuzzy logic techniques to analyze the IME and Discrete engine systems. Uncertainty analyses are stressed in this report because we recognize that the component failure probabilities used are uncertain and vague. The results of the demandbased failure and the time-based failure data base are presented in the following sections. All other demand-based and time-based failure data were obtained from references 7 and 10, except the data for the controllers, the injector housing, and the actuator source (which were assumed to be 100-percent reliable) and for the sensors (which were assigned a failure probability of $1.0 \times 10^{-6}$ ). Neither the flow lines, with the exception of manifolds, nor the IME turbine bypass valves discussed in reference 7 are considered in this report. All component failures in both the demand-based and time-based analyses were treated as uncorrelated events; that is, each component failed independent of all other components and their operational condition.

\section{Demand-Based Failure Data Base}

The results from the Monte Carlo sampling technique used in the demand-based probabilistic analyses of the Discrete and IME systems are summarized in Table 2. Two values for the manifold failure probability, $1 \times 10^{-5}$ and $1 \times 10^{-6}$, were used to investigate the effects of manifold failure probability on system reliability.

From the table we can see that there were only small differences (less than 1 percent) between the mini$\mathrm{mal}$ cut set (the point estimates based on the mean failure rate of each component) and the mean value from the Monte Carlo simulations. In addition, the selection of the component distribution (normal or lognormal) did not appear to affect the mean values. Also, system coefficients of variation were less than 5 percent of the mean, compared to 20 percent of the mean for the component CoV's. Finally, for most cases the coefficient of skewness is approximately 0 and the kurtosis is approximately 3 . These values indicate that the system failure rate distribution is nearly a normal distribution.

For reliability analyses of systems with high degrees of uncertainty, it is important to stress relative comparisons between systems rather than the absolute values of the reliability estimates. Such comparisons for the Discrete and IME systems are made in Fig. 6, which shows the results of using IME manifold failure probabil- 
ities (P, man) of $1.0 \times 10^{-5}$ and $1.0 \times 10^{-6}$, with a 20 -percent component $\mathrm{CoV}$. From this figure it is clear that the Discrete system is more reliable than the IME if we assume a manifold failure probability of $1.0 \times 10^{-5}$. From a calculation using the mean and standard deviation of the two distributions, ${ }^{16}$ the IME had only a 0.0003 probability of being more reliable than the Discrete engine system. Although the IME has fewer components (and fewer minimal cut sets) than the Discrete system, the reliance on those few components is high. This is especially true of the manifolds which represent single point failures. The F-V importance factors provided by the IRRAS code also indicated that for these failure probabilities the manifolds were the most significant contributors to failure in the IME, followed by the valves.

When a lower value is chosen for the manifold failure rate $\left(1.0 \times 10^{-6}\right)$, as shown in Fig. 6, the IME becomes more reliable than the Discrete system. The data in Table 2 indicate that the IME had a 0.998 probability of being more reliable than the Discrete engine system with a reduced manifold failure probability. Under these conditions the manifolds were no longer the most significant contributor to failure. The F-V importance factors showed that the valves were the most likely cause of IME system failure. These results confirm those obtained in reference 7, which state that the IME can be made to be more reliable than the Discrete system if the manifold reliability is high. In addition, the results indicate that although much effort should be spent on making the manifolds more reliable in the IME, significant consideration should be placed on improving valve reliability as well.

The results for the demand-based fuzzy logic fault tree analysis using FUZZYFTA are shown in Fig. 7. For the case where the IME manifold failure probability was $1.0 \times 10^{-5}$, the IME clearly had a higher failure probability than the Discrete system. However, in contrast to the probabilistic results shown in Fig. 6, there was significant overlap in the fuzzy sets. Because of the overlap of the fuzzy sets, a calculation based on correlations in reference 17 was performed to determine the probability that the IME was more reliable than the Discrete engine. The probability was determined by dividing the overlap area by the total area of the two fuzzy sets. The calculation showed that the IME had a 0.139 probability of being more reliable than the Discrete engine. This value is considerably higher than the value obtained by using the probabilistic analysis, thereby reflecting the overlap of the fuzzy sets. Figure 7 also shows similar results for the case in which the IME manifold reliability was assumed to be $1 \times 10^{-6}$. As in the probabilistic analyses, the IME was more reliable than the Discrete system when the lower manifold failure probability was used; it had a 0.676 probability of being more reliable than the Discrete engine system for this manifold failure probability. The fuzzy sets again showed significant overlap, however. The importance factors calculated by FUZZYFTA were also similar to those calculated by IRRAS, with the valves being the most significant contributor to the system risk in the IME when the manifold failure probability was reduced.

\section{Time-Based Failure Data Base}

The time-based analyses of the Discrete and IME systems were conducted with a baseline system operation time of $400 \mathrm{~s}$. This operation time was selected as typical of a single engine firing, which agrees with the manner in which the failure rate values were established in reference 10. Although a single mission time was selected, previous Markov analyses have demonstrated that the probability of system failure nonlinearly increases with increasing duration of system operation. ${ }^{7}$ This observation has been confirmed with the present fault tree analyses.

The results of the time-based probabilistic system analyses are shown in Table 3. Some general conclusions can be drawn from an overview of the first four system failure probability distribution moments generated from the Monte Carlo simulations. The means and medians were approximately equal to the calculated point estimates (min. cut upper bound); the greatest difference was 1.55 percent. System CoV's were much smaller than the assumed component CoV's. The component distribution type (normal or lognormal) had little effect on the system CoV's, but clearly played a role in skewness. The system distributions exhibited normal distribution characteristics: coefficients of skewness near 0 and coefficients of kurtosis approximately 3. Prior to the analyses we did not know that the system distributions would be nearly normal. This result could, however, be affected by differences in system configuration in future designs.

The Discrete system exhibited a point estimate failure probability of 0.2126 , and the IME system demonstrated a 0.2584 point estimate failure probability based on reference 7 manifold failure rates, which are the baseline values shown in Table 3 . Figure 8 graphically compares the uncertainty results of these two rocket engine systems with different manifold reliabilities. With 20-percent component $\mathrm{CoV}$, the IME system has a 0.007 probability of being more reliable than the Discrete system. The conclusion that the IME system is, in general, less reliable than the Discrete system becomes clearer when the minimal cut sets from the IME fault tree are studied. Although the IME system has 1290 fewer cut sets than the Discrete system, the IME system is vulnerable to those cut sets composed of 1 basic event (single point failures), particularly the manifolds. This conclusion was further supported by the F-V importance measure, which was largest for these manifolds. 
By reducing the failure probability of all IME system manifolds to 0.0001 , the findings detailed in the previous paragraph were reversed. Figure 8 compares the two rocket engine systems under the revised manifold failure rate condition of $1 \times 10^{-4}$. Now, with a 20-percent component $\mathrm{CoV}$, the IME system has a 0.995 probability of being more reliable than the Discrete system. With the reduced rate for manifold failure, the thrust chambers become the most critical components contributing to the unreliability of both the Discrete and IME systems, as indicated by the F-V importance measure. This happens because the combustion chambers have the highest component failure rate, and the relative importance of the single point manifold failures has diminished. These results differ significantly from those obtained with the demandbased failure data base, which showed that the valves were the biggest contributor to failure with a reduced manifold failure probability.

The results from the time-based fuzzy logic system analysis with the FUZZYFTA code are graphically presented in Fig. 9. The results of the time-based analysis showed that the IME had a 0.251 probability of being more reliable than the Discrete system. By reducing all manifold failure rates to 0.0001 , the IME system fuzzy failure probability was reduced, thus making the IME system more reliable than the Discrete system. On the basis of the lower manifold failure probability the IME had a 0.715 probability of being more reliable than the Discrete system. These results are similar to the probabilistic analyses conducted with the IRRAS code. It is interesting to note, however, that the importance factors ${ }^{15}$ calculated for all fuzzy fault tree analyses ranked the combustion chambers as the most critical component in improving system reliability even when high manifold failure rates were used. This is in contrast to the F.V importance measure in the probabilistic analysis which ranked the manifolds as the major contributors to the minimal cut upper bound for the IME high manifold failure rate case. These results seem to indicate that refinements must be made in the importance calculations for fuzzy fault tree analyses.

Examination of the demand-based and timebased data showed that system uncertainty was actually larger than component uncertainty in the fuzzy fault tree approach. For instance, when the most likely probability of component failure was \pm 10 percent, in the Discrete system the most likely probability of system failure was approximately \pm 20 percent of the point estimate. In contrast, when a component standard deviation of 20 percent was used for the probabilistic analysis, the Discrete system failure probability had a standard deviation of approximately 5 percent. Therefore, system uncertainty was less than component uncertainty in the probabilistic approach. In addition, the fuzzy logic fault tree results have demonstrated extreme values which were larger than the minimum/maximum values calculated in the probabi- listic analyses. On the basis of these results, the fuzzy logic technique is apparently more conservative than the probabilistic approach.

When we examine both the demand-based and time-based results, it is important to note the differences between the probabilistic distributions and fuzzy sets. In the probabilistic distribution, only 68 percent of the normal distribution is bounded by \pm 1 standard deviation, whereas in the fuzzy logic example the entire possibility of failure is bounded within the description of the fuzzy set. In addition, as noted in reference 16, the fuzzy logic approximations used to calculate the failure probability will provide a conservative result. Because of these factors, the fuzzy sets show significant overlap in contrast to the probabilistic comparison.

The time-based probabilistic system analysis results shown in Table 3 are four to five orders of magnitude larger than the demand-based analysis results reported in Table 2. This was also true for the fuzzy logic results in Figs. 7 and 9. This difference is a direct result of using different failure rates and different calculation procedures. However, the importance of the analysis lies in the relative comparison of the systems, rather than the absolute magnitude of the failure probabilities. General trends that are observed in one analysis approach, whether it be based on demand or time, can be compared to the trends observed in another analysis approach if relative differences are considered.

\section{Fuzzy Logic and Probability}

In the analyses described in this report, probabilistic and fuzzy logic techniques were used. These are techniques that are used to try to estimate uncertainty in a system. But all uncertainty is not the same. Random uncertainty describes the chances that a single value might be achieved, whereas vagueness describes a range of possible values. Probabilistic analyses describe random uncertainty whereas fuzzy logic analyses deal with vagueness in the system. To fully understand a system, it is necessary to acknowledge and determine both types of uncertainty. This is especially true for descriptions of hardware failures. Some components fail completely, whereas others fail partially. Or the component has more than one failure rate because the system is not operated the same way each time it is turned on. In addition, human interactions with hardware consist of both random and vague actions, which also affect the failure rates of systems.

With probabilistic approaches to fault tree analyses, we can determine the system failure probability and uncertainty on the basis of defined fault tree logic and component failure probability distributions. Uncertainty in the failure rate is quantified through the distribution type and the distribution moments (mean, variance, etc.). 
With the fuzzy logic fault tree approach, we can determine system failure probability on the basis of defined fault tree logic and vagueness in component failure rates. Fuzzy sets are used instead of distributions to describe component failure rate uncertainty, and those fuzzy sets are manipulated on the basis of fault tree logic to obtain an estimate of the system failure probability and uncertainty. The analyses here showed that the system uncertainty calculated by using the probabilistic approach was less than the assumed component uncertainty. In contrast, the fuzzy logic approach calculated system vagueness, which was larger than the assumed component vagueness. In addition, the most likely system failure probability regions calculated from the fuzzy fault tree analyses are broader than the 90 -percent confidence intervals determined from the probabilistic fault tree analyses. This result reinforces the belief that the probabilistic approach is merely a subset of the fuzzy logic technique.

Currently, fuzzy logic techniques are not as sophisticated as probabilistic techniques in analyzing system reliability. For instance, it is clear from this analysis that the importance factors in the fuzzy fault tree approach need to be refined. Fuzzy logic techniques hold promise, however, in treating vagueness in system reliability analyses. As shown here, the technique is intuitive to an engineer's understanding of uncertainty and represents a valid approach for treating situations lacking in comprehensive data. Further development of fuzzy logic techniques could add another tool for analyzing the uncertainty of engineering systems.

\section{Concluding Remarks}

Probabilistic and fuzzy logic techniques were used in a study to evaluate the reliability of rocket engine systems. Fault trees were developed for the Integrated Modular Engine (IME) and the Discrete engine systems. These fault trees were quantified probabilistically by using the IRRAS computer code, developed for the U.S. Nuclear Regulatory Commission. Fuzzy logic analyses were performed using FUZZYFTA, a model developed at NASA Lewis Research Center for the quantification of fuzzy fault trees.

On the basis of assumptions used in this study, the Discrete system was found to be more reliable than the IME for the baseline cases studied. The IME was found to be more reliable than the Discrete engine only under conditions of significantly improved manifold reliability. These results were the same for both the probabilistic and the fuzzy logic approaches. However, the fuzzy logic technique showed a larger range of uncertainty in the results than did the probabilistic technique. Also, the results of the analyses indicated that in addition to manifolds, valves and combustion chambers were key reliability drivers.
For many systems, component reliability data are uncertain, which increases the difficulty in determining system risk. Therefore, analyses are required to ensure that uncertainty is neither misunderstood nor ignored. This becomes especially important during the initial design phase of a project, when modifications can be made prior to hardware construction. Because uncertainty includes both random and vague components, multiple techniques are necessary for determining system reliability. The analyses presented here show that both probabilistic and fuzzy logic techniques are extremely useful tools in determining and managing uncertainty in rocket engine systems.

\section{Acknowledgment}

The authors wish to acknowledge Peter Rutledge and Benjamin Buchbinder of NASA Headquarters for their support of this research.

\section{References}

1. Fragola, J.R., "A Second Look at Launch System Reliability," Aerospace America, Vol. 29, Nov. 1991, pp. 36-39.

2. Wu, J.S., and Apostolakis, G.E., "Experience with Probabilistic Risk Assessment in the Nuclear Power Industry," Joumal of Hazardous Materials, Vol. 29, No. 3, Feb. 1992, pp. 313-345.

3. Garrick, B.J., "The Approach to Risk Analysis in Three Industries: Nuclear Power, Space Systems, and Chemical Process," Reliability Engineering and System Safety, Vol. 23, 1988, pp. 195-202.

4. Buchbinder, B., "Risk Management for the Space Exploration Initiative," AIAA Paper 93-0377, 1993.

5. Park, K.S., "Fuzzy Apportionment of System Reliability," IEEE Transactions on Reliability, Vol. R-36, No. 1, Apr. 1987, pp. 129-132.

6. Gazdik, I., "Fault Diagnosis and Prevention by Fuzzy Sets," IEEE Transactions on Reliability, Vol. R-34, Oct. 1985, pp. 382-388.

7. Hardy, T.L.; and Rapp, D.C., "Reliability Studies of Integrated Modular Engine System Designs," AIAA Paper 93-1886, 1993.

8. Binder, M.P., and Felder, J.L., "Predicted Performance of an Integrated Modular Engine System," AIAA Paper 93-1888, 1993.

9. Frankenfield, F., and Carek, J., "Fluid System Design Studies of Integrated Modular Engine System," AIAA Paper 93-1887, 1993. 
10. Parsley, R.; and Ward, T., "Integrated Modular Engine - Reliability Assessment," AIAA Paper 92$3695,1992$.

11. Kapur, K.C., and Lamberson, L.R., Reliabilicy in EngineeringDesign. John Wiley \& Sons, New York, 1977.

12. Russell, K.D., Sattison, M.B., and Rasmuson, D.M., "Integrated Reliability and Risk Analysis System (IRRAS), Version 4.0," Report NUREG/CR-5813, EGG-2664, Office of Radiation Programs, Washington, D.C., 1992.

13. Vesely, W.E., Haasl, D.F., Roberts, N.H., and Goldberg, F.F., "Fault Tree Handbook," Report NUREG0492, U.S. Nuclear Regulatory Commission, 1981.
14. Zadeh, L., "Fuzzy Sets," Information \& Control, Vol. 8, 1965, pp. 338-353.

15. Lai, F.S., Shenoi, S., and Fan, L.T., "Fuzzy Fault Tree Analysis: Theory and Application," Engineering Risk and Hazard Assessment. Volume I, Kandel, A., and Avni, E., ed., CRC Press, Inc., Boca Raton, FL,1988.

16. Tanaka, H., Fan, L.T., Lai, F.S., and Toguchi, K., "Fault Tree Analysis by Fuzzy Probability," IEEE Transactions on Reliability, Vol. R32, No. 5, Dec. 1983, pp. 453-457.

17. Bellman, R.E., and Zadeh, L.A., "Decision-Making in a Fuzzy Environment," NASA CR-1594, 1970.

TABLE 1. - MATHEMATICAL RELATIONS FOR PROBABILISTIC AND FUZZY FAULT TREE ANALYSES

(From references 12 and 16)

\begin{tabular}{|c|c|c|}
\hline Gate type & Probabilistic relation & Fuzzy logic relation \\
\hline $\begin{array}{c}\text { AND } \\
\text { (2 inputs) }\end{array}$ & $\mathrm{P}=\mathrm{P}_{1} \mathrm{P}_{2}$ & $\begin{array}{l}P=P_{1} \odot P_{2} \\
P=\left(q_{1,1} q_{1,2}, p_{1,1} p_{1,2}, p_{r, 1} p_{r, 2}, q_{r, 1} q_{r, 2}\right)\end{array}$ \\
\hline $\begin{array}{c}\text { OR } \\
\text { (2 inputs) }\end{array}$ & $P=1-\left(1-P_{1}\right)\left(1-P_{2}\right)$ & $\begin{array}{l}P_{t, 1}=1-P_{1} \\
P_{t, 1}=\left(1-q_{r, 1}, 1-P_{r, 1}, 1-p_{1,1}, 1-q_{1,1}\right) \\
P_{t, 2}=1-P_{2} \\
P_{t, 2}=\left(1-q_{r, 2}, 1-P_{r, 2}, 1-p_{1,2}, 1-q_{1,2}\right) \\
P=1-P_{t, 2} \odot P_{t, 2}\end{array}$ \\
\hline N/M & $\begin{array}{l}P_{1}=P_{2}=P_{3}=\ldots \\
C=M ! /(N !(M-N) !) \\
P=1-\left(1-P_{1}^{2}\right)^{C}\end{array}$ & $\begin{array}{l}P_{1}=P_{2}=P_{3}=\ldots \\
C=M ! /(N !(M-N) !) \\
P_{1}{ }^{2}=\left(q_{1,1}{ }^{2}, p_{1,1}{ }^{2}, p_{r, 1}{ }^{2}, q_{r, 1}{ }^{2}\right) \\
1-P_{1}{ }^{2}=\left(1-q_{r, 1}{ }^{2}, 1-p_{r, 1}{ }^{2}, 1-p_{1,1}{ }^{2}, 1-q_{1,1}{ }^{2}\right) \\
P=1-\left(1-P_{1}{ }^{2}\right)^{C}\end{array}$ \\
\hline
\end{tabular}

Where

$$
\begin{aligned}
\mathrm{P} & =\text { Gate probability; } \\
\mathrm{P}_{1}, \mathrm{P}_{2}, \mathrm{P}_{3} & =\text { Bottom event (input) probability; } \\
\mathrm{q}_{1} & =\text { Left extreme value of trapezoidal fuzzy set; } \\
\mathrm{p}_{1} & =\text { Left interior value of trapezoidal fuzzy set; } \\
\mathrm{p}_{\mathbf{r}} & =\text { Right interior value of trapezoidal fuzzy set; } \\
\mathrm{q}_{\mathbf{r}} & =\text { Right extreme value of trapezoidal fuzzy set; } \\
\mathrm{N} & =\text { Number of input events (out of } \mathrm{M} \text { ) which must } \\
\mathbf{M} & =\text { occur for the N/M gate failure to occur; }
\end{aligned}
$$


TABLE 2. - DEMAND-BASED PROBABILISTIC SYSTEM ANALYSES (IRRAS), MONTE CARLO SAMPLING, 2000 SAMPLES

a) Discrete Engine System (point estimate $=7.018 \times 10^{-5}$ )

\begin{tabular}{|c|c|c|}
\hline Component Distribution & Normal & Lognormal \\
\hline Component CoV & $20 \%$ & $20 \%$ \\
\hline $\operatorname{Mean}\left(\times 10^{-5}\right)$ & 7.004 & 7.025 \\
\hline Median $\left(\times 10^{-5}\right)$ & 6.998 & 7.019 \\
\hline 5th Percentile $\left(x 10^{-5}\right)$ & 6.455 & 6.477 \\
\hline 95th Percentile $\left(x 10^{-5}\right)$ & 7.568 & 7.596 \\
\hline Minimum $\left(\times 10^{-5}\right)$ & 5.847 & 5.828 \\
\hline Maximum $\left(\times 10^{5}\right)$ & 8.098 & 8.490 \\
\hline Standard Deviation $\left(\times 10^{-6}\right)$ & 3.396 & 3.439 \\
\hline Coefficient of Variation & $4.8 \%$ & $4.9 \%$ \\
\hline Coefficient of Skewness & .0143 & .1383 \\
\hline Coefficient of Kurtosis & 3.083 & 3.111 \\
\hline
\end{tabular}

b) Integrated Modular Engine system (point estimate $=1.027 \times 10^{-4}$ ), manifold failure probability $=1.0 \times 10^{-5}$

\begin{tabular}{|c|c|c|}
\hline Component Distribution & Normal & Lognormal \\
\hline Component CoV & $20 \%$ & $20 \%$ \\
\hline $\operatorname{Mean}\left(\times 10^{-4}\right)$ & 1.027 & 1.027 \\
\hline Median $\left(\times 10^{-4}\right)$ & 1.026 & 1.025 \\
\hline 5th Percentile $\left(x 10^{-4}\right)$ & 0.946 & 0.947 \\
\hline 95th Percentile $\left(x 10^{-4}\right)$ & 1.109 & 1.118 \\
\hline Minimum $\left(x 10^{-4}\right)$ & 0.853 & 0.875 \\
\hline Maximum $\left(\times 10^{-4}\right)$ & 1.172 & 1.238 \\
\hline Standard Deviation $\left(\times 10^{-6}\right)$ & 4.945 & 5.173 \\
\hline Coefficient of Variation & $4.8 \%$ & $5.0 \%$ \\
\hline Coefficient of Skewness & -.0025 & .2756 \\
\hline Coefficient of Kurtosis & 2.967 & 3.100 \\
\hline
\end{tabular}

c) Integrated Modular Engine system (point estimate $=5.778 \times 10^{-5}$ ), manifold failure probability $=1.0 \times 10^{-6}$

\begin{tabular}{|l|c|c|}
\hline Component Distribution & Normal & Lognormal \\
\hline Component CoV & $20 \%$ & $20 \%$ \\
\hline Mean $\left(\times 10^{-5}\right)$ & 5.781 & 5.777 \\
\hline Median $\left(\times 10^{-5}\right)$ & 5.781 & 5.773 \\
\hline 5th Percentile $\left(\times 10^{-5}\right)$ & 5.400 & 5.403 \\
\hline 95 th Percentile $\left(\times 10^{-5}\right)$ & 6.167 & 6.181 \\
\hline Minimum $\left(\times 10^{-5}\right)$ & 5.093 & 5.045 \\
\hline Maximum (x10 & 6.602 & 6.833 \\
\hline Standard Deviation $\left(\times 10^{-5}\right)$ & 2.358 & 2.345 \\
\hline Coefficient of Variation & $4.1 \%$ & $4.1 \%$ \\
\hline Coefficient of Skewness & .0840 & .1294 \\
\hline Coefficient of Kurtosis & 2.977 & 3.285 \\
\hline
\end{tabular}


TABLE 3. - TIME-BASED PROBABILISTIC SYSTEM ANALYSES (IRRAS), MONTE CARLO SAMPLING, 2000 SAMPLES

a) Discrete Engine System (point estimate $=0.2126$ )

\begin{tabular}{|l|c|c|}
\hline Component Distribution & Normal & Lognormal \\
\hline Component CoV & $20 \%$ & $20 \%$ \\
\hline Mean $\left(\times 10^{-1}\right)$ & 2.123 & 2.125 \\
\hline Median $\left(\times 10^{-1}\right)$ & 2.123 & 2.121 \\
\hline Sth Percentile $\left(\times 10^{-1}\right)$ & 1.910 & 1.915 \\
\hline 95 th Percentile $\left(\times 10^{-1}\right)$ & 2.350 & 2.360 \\
\hline Minimum $\left(\times 10^{-1}\right)$ & 1.664 & 1.737 \\
\hline Maximum $\left(\times 10^{-1}\right)$ & 2.632 & 2.702 \\
\hline Standard Deviation $\left(\times 10^{-2}\right)$ & 1.318 & 1.341 \\
\hline Coefficient of Variation & $6.2 \%$ & $6.3 \%$ \\
\hline Coefficient of Skewness & .06747 & .2313 \\
\hline Coefficient of Kurtosis & 3.085 & 3.145 \\
\hline
\end{tabular}

b) Integrated Modular Engine system (point estimate $=0.2584$ ), manifold \#1 failure rate $=0.0264 / 1000 \mathrm{~s}$ (failure probability $=.0105$ ), manifolds $\# 2-5$ failure rate $=0.066 / 1000 \mathrm{~s}$ (failure probability $=.0261$ ) (baseline)

\begin{tabular}{|l|c|c|}
\hline Component Distribution & Normal & Lognormal \\
\hline Component CoV & $20 \%$ & $20 \%$ \\
\hline Mean $\left(\times 10^{-1}\right)$ & 2.581 & 2.585 \\
\hline Median $\left(\times 10^{-1}\right)$ & 2.580 & 2.578 \\
\hline 5th Percentile $\left(\times 10^{-1}\right)$ & 2.369 & 2.371 \\
\hline 95 th Percentile $\left(\times 10^{-1}\right)$ & 2.803 & 2.817 \\
\hline Minimum $\left(\times 10^{-1}\right)$ & 2.155 & 2.195 \\
\hline Maximum $\left(\times 10^{-1}\right)$ & 3.050 & 3.091 \\
\hline Standard Deviation $\left(\times 10^{-2}\right)$ & 1.310 & 1.342 \\
\hline Coefficient of Variation & $5.1 \%$ & $5.2 \%$ \\
\hline Coefficient of Skewness & .08594 & .1302 \\
\hline Coefficient of Kurtosis & 3.131 & 2.829 \\
\hline
\end{tabular}

c) Integrated Modular Engine system (point estimate $=0.1675$ ), manifold failure rate $=.00025 / 1000 \mathrm{~s}$ (manifold failure probability $=0.0001$ )

\begin{tabular}{|l|c|c|}
\hline Component Distribution & Normal & Lognormal \\
\hline Component CoV & $20 \%$ & $20 \%$ \\
\hline Mean $\left(\times 10^{-1}\right)$ & 1.676 & 1.672 \\
\hline Median $\left(\times 10^{-1}\right)$ & 1.676 & 1.668 \\
\hline Sth Percentile $\left(\times 10^{-1}\right)$ & 1.491 & 1.488 \\
\hline 95 th Percentile $\left(\times 10^{-1}\right)$ & 1.869 & 1.875 \\
\hline Minimum $\left(\times 10^{-1}\right)$ & 1.330 & 1.314 \\
\hline Maximum $\left(\times 10^{-1}\right)$ & 2.071 & 2.181 \\
\hline Standard Deviation $\left(\times 10^{-2}\right)$ & 1.151 & 1.178 \\
\hline Coefficient of Variation & $6.9 \%$ & $7.0 \%$ \\
\hline Coefficient of Skewness & .1167 & .3271 \\
\hline Coefficient of Kurtosis & 2.907 & 3.322 \\
\hline
\end{tabular}




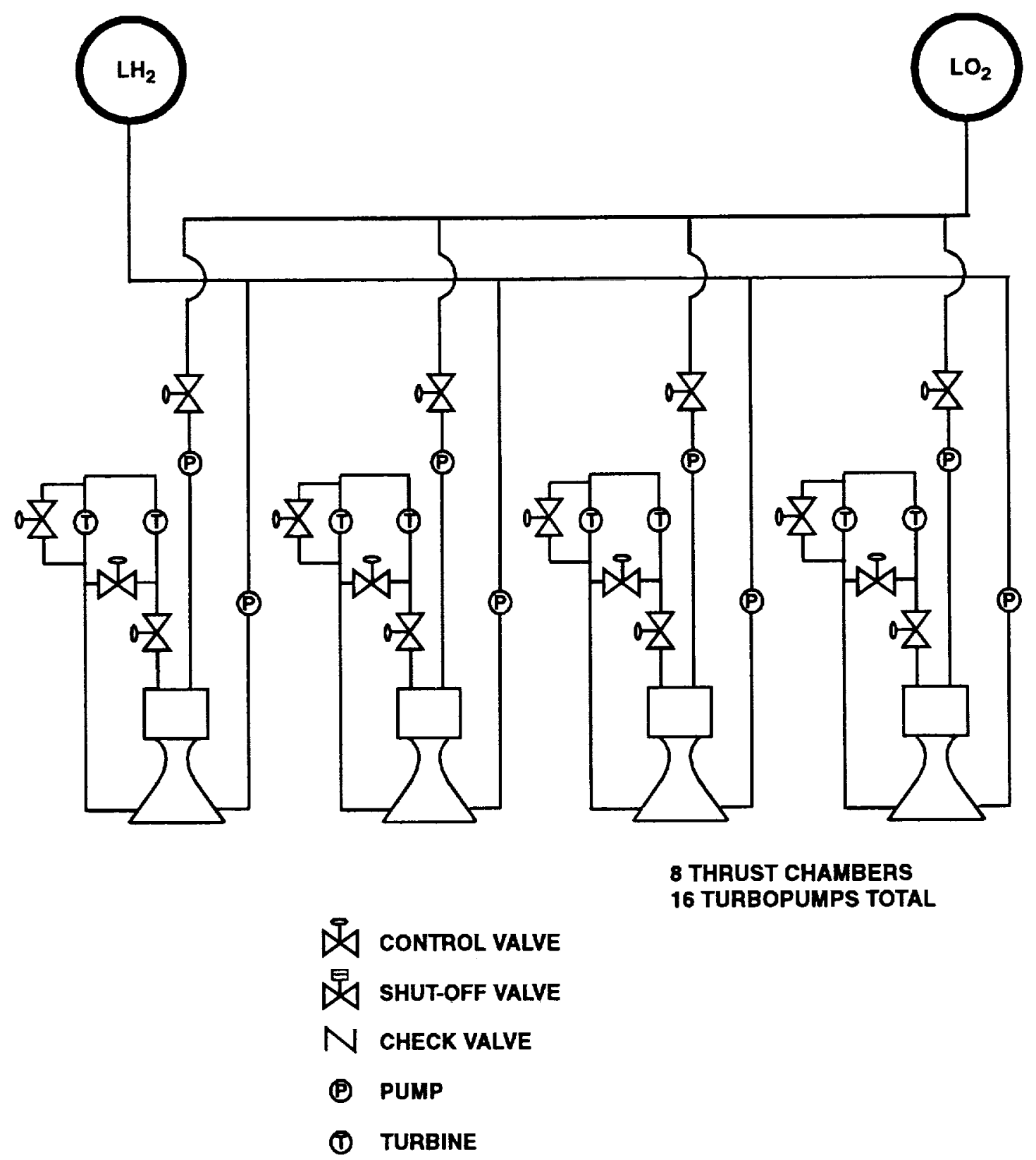

Figure 1.- Discrete engine diagram, expander cycle configuration. 


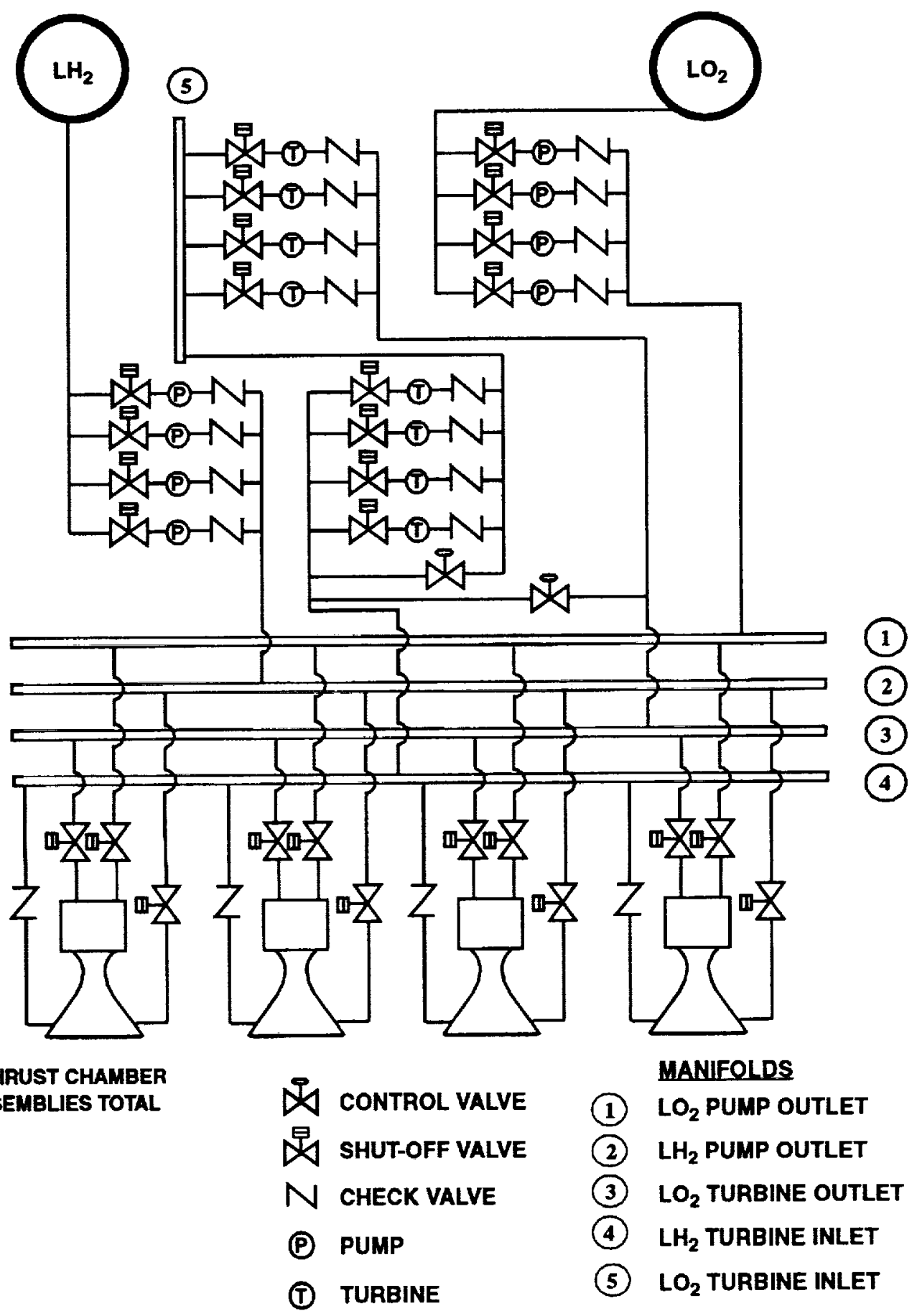

Figure 2.- Integrated Modular Engine diagram, expander cycle configuration. 


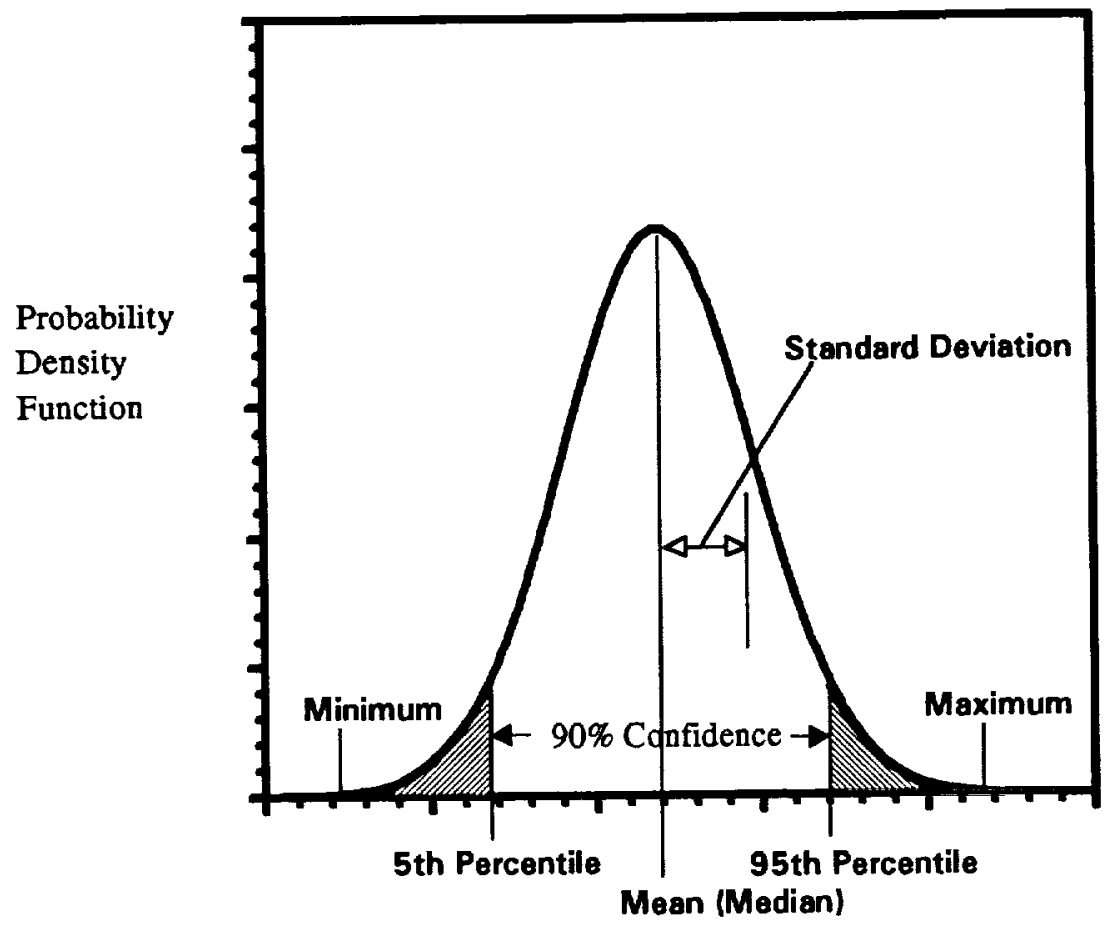

Failure Probability

Figure 3.- Normal failure rate probability distribution.

Membership

Function

Membership Function
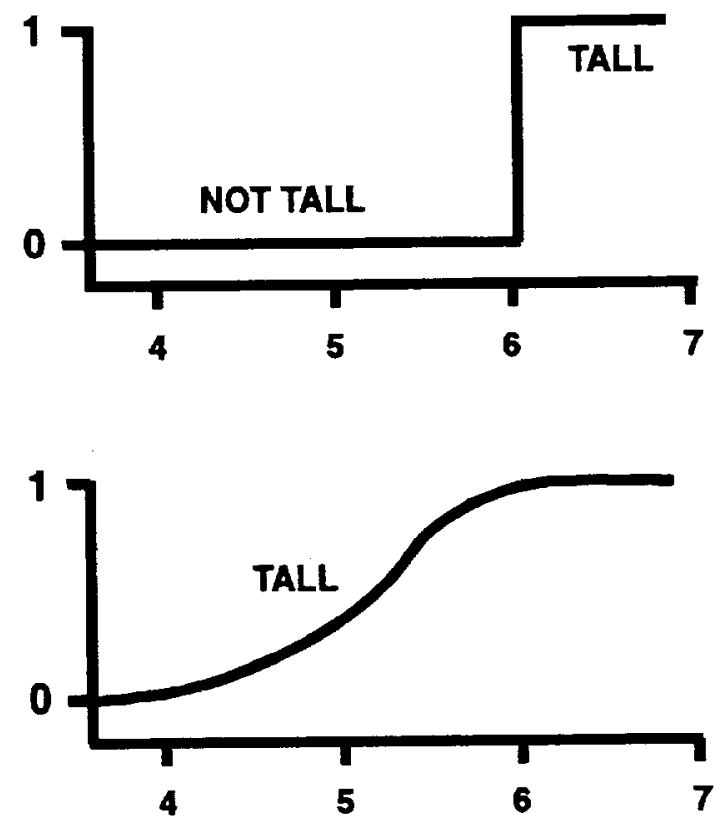

Height, ft
BIVALENT

(CLASSICAL)

SET

\section{MULTIVALENT \\ (FUZZY) \\ SET}

Figure 4.- Comparison of classical and fuzzy sets. 


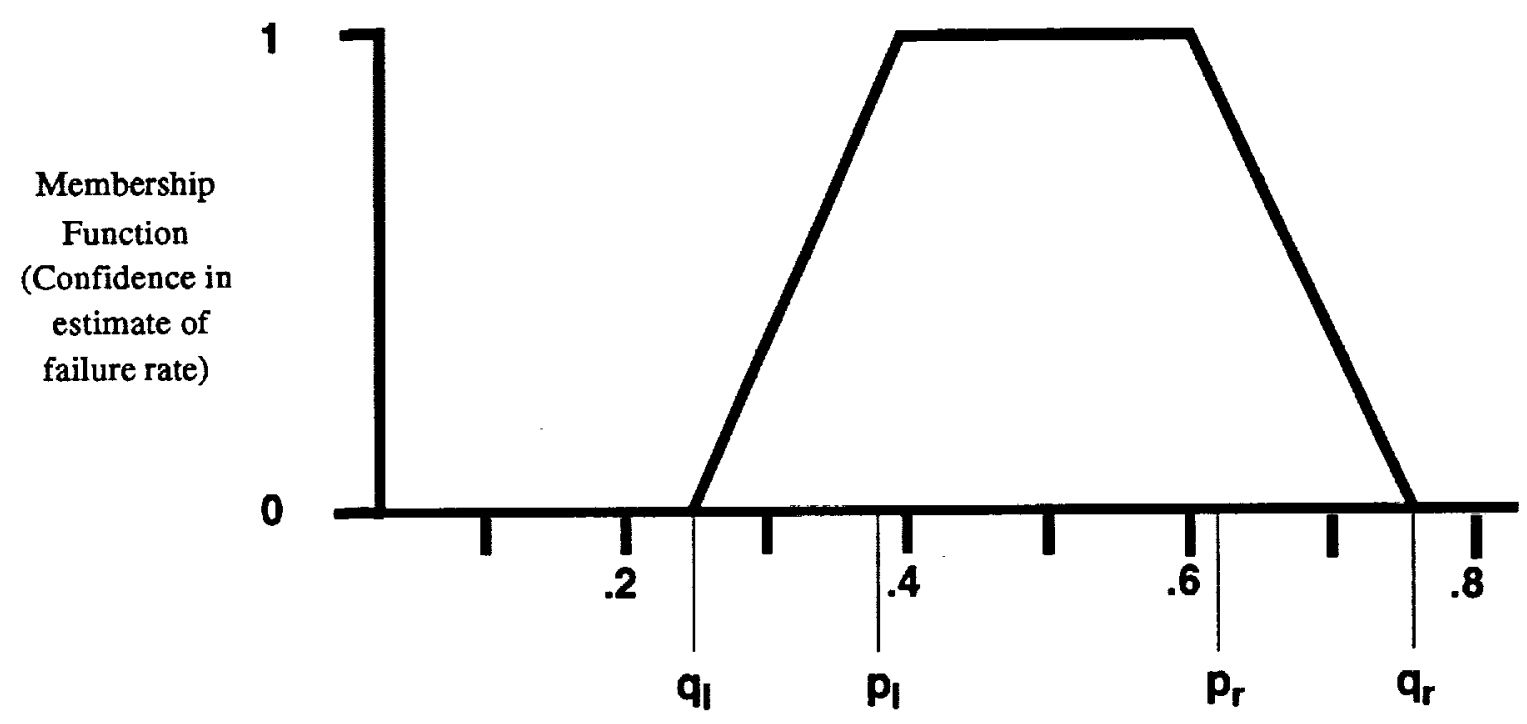

Failure probability

Figure 5.- Trapezoidal fuzzy set.

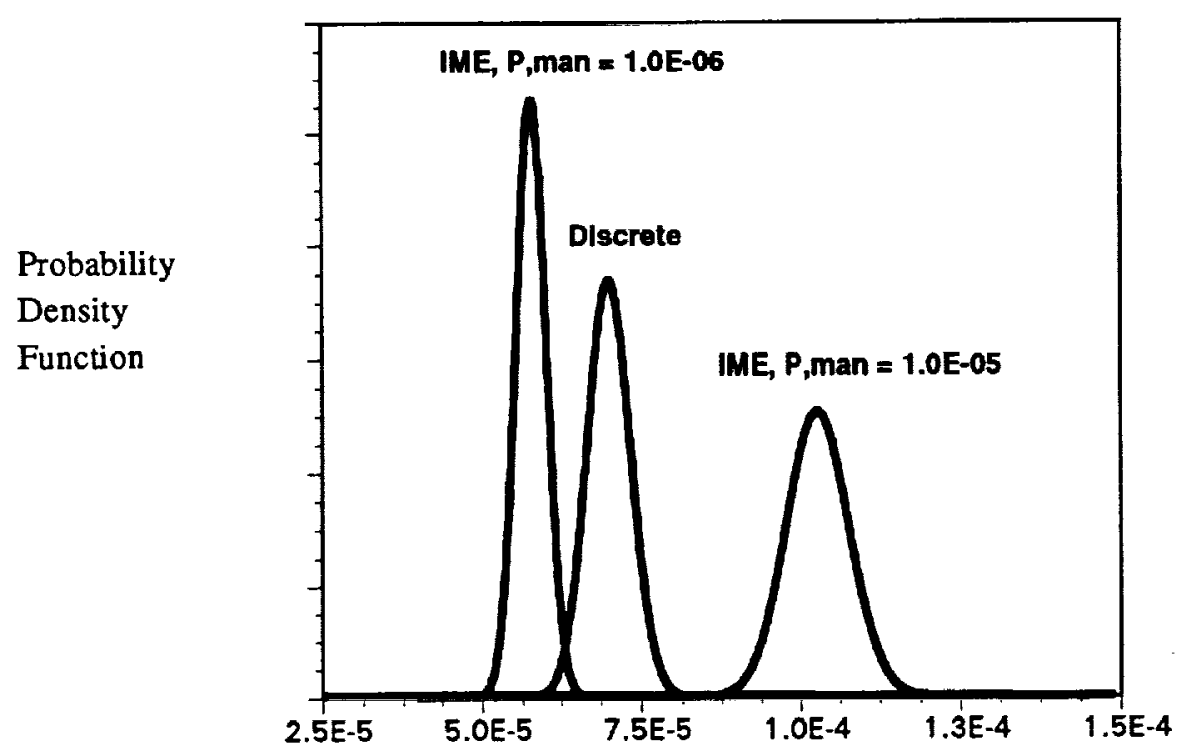

Failure probability

Figure 6.- Comparison of demand-based IME and Discrete engine system failure probability distributions. 


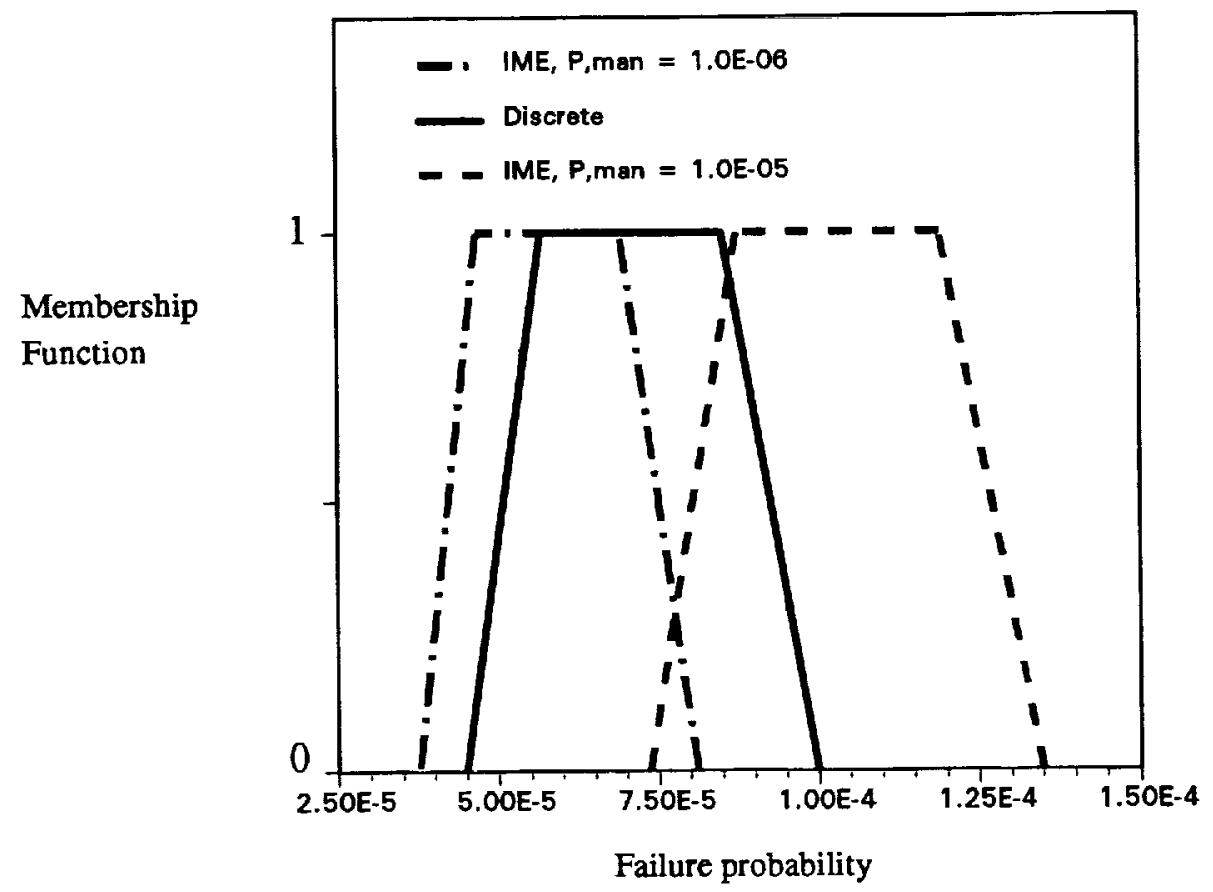

Figure 7.- Comparison of demand-based $\mathrm{MME}$ and Discrete engine system failure probability fuzzy sets.

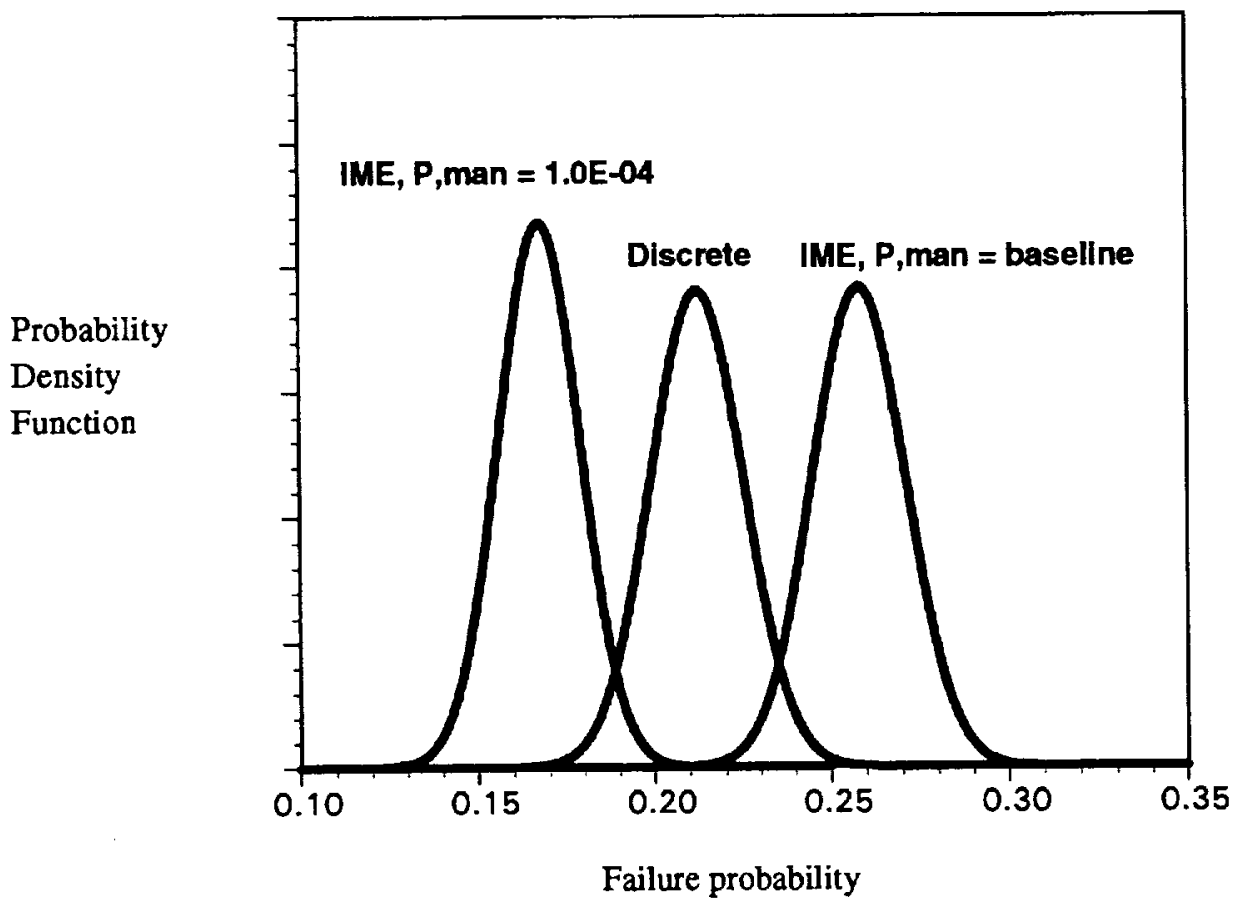

Figure 8.- Comparison of time-based IME and Discrete engine system failure probability distributions. 


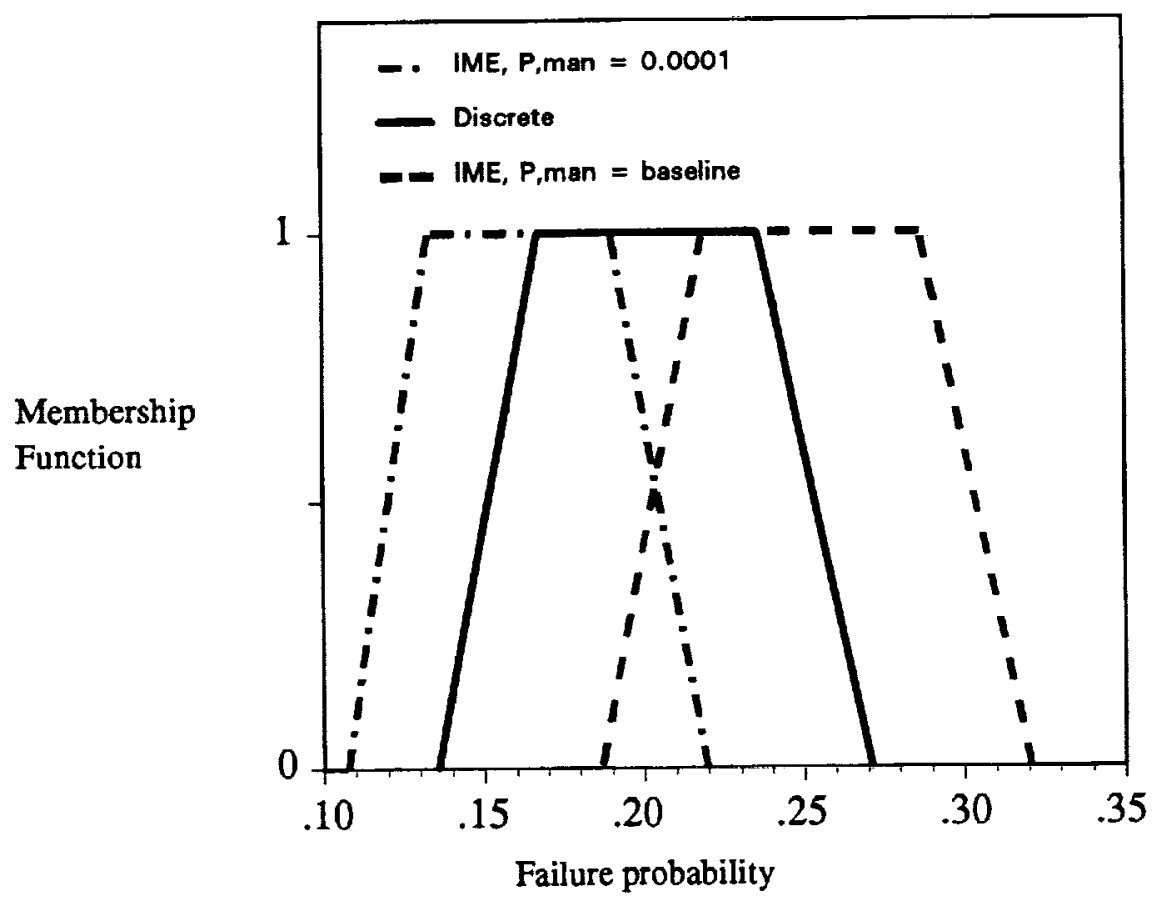

Figure 9.- Comparison of time-based IME and Discrete engine system failure probability fuzzy sets. 


\section{.}

,

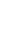


Public reporting burden for this collection of information is estimated to average 1 hour per response, including the time for reviewing instructions, searching exlsting data sources. gathering and maintaining the data needed, and completing and reviewing the collection of information. Send comments regarding this burden estimate or any other aspect of this collection of intomation, including suggestions for reducing this burden,

\begin{tabular}{|l|c|c|}
\hline 1. AGENCY USE ONLY (Leave blank) & $\begin{array}{r}\text { 2. REPORT DATE } \\
\text { April } 1994\end{array}$ & $\begin{array}{r}\text { 3. REPORT TYPE AND DATES COVERED } \\
\text { Technical Memorandum }\end{array}$ \\
\hline
\end{tabular}

\section{TITLE AND SUBTITLE}

5. FUNDING NUMBERS

Rocket Engine System Reliability Analyses Using Probabilistic and Fuzzy Logic Techniques

6. AUTHOR(S)

WU-506-42-72

Terry L. Hardy and Douglas C. Rapp

7. PERFORMING ORGANIZATION NAME(S) AND ADDRESS(ES)

8. PERFORMING ORGANIZATION REPORT NUMBER

National Aeronautics and Space Administration

Lewis Research Center

Cleveland, Ohio 44135-3191

E-8640

9. SPONSORING/MONITORING AGENCY NAME(S) AND ADDRESS(ES)

10. SPONSORINGMONITORING AGENCY REPORT NUMBER

National Aeronautics and Space Administration

NASA TM-106519

Washington, D.C. 20546-0001

AIAA-94-2750

11. SUPPLEMENTARY NOTES

Prepared for the 30th Joint Propulsion Conference cosponsored by the AIAA, ASME, SAE, and ASEE, Indianapolis, Indiana, June 27-29, 1994. Terry L. Hardy, NASA Lewis Research Center; and Douglas C. Rapp, Sverdrup Technology, Inc., Lewis

Research Center Group, 2001 Aerospace Parkway, Brook Park, Ohio 44142. Responsible person, Terry L. Hardy, organization code 5300, (216) 433-7517.

12a. DISTRIBUTIONAVAILABILITY STATEMENT

12b. DISTRIBUTION CODE

Unclassified - Unlimited

Subject Category 20

13. ABSTAACT (Maximum 200 words)

The reliability of rocket engine systems was analyzed by using probabilistic and fuzzy logic techniques. Fault trees were developed for Integrated Modular Engine (IME) and Discrete engine systems, and then were used with the two techniques to quantify reliability. The IRRAS (Integrated Reliability and Risk Analysis System) computer code, developed for the U.S. Nuclear Regulatory Commission, was used for the probabilistic analyses, and FUZZYFTA (Fuzzy Fault Tree Analysis), a code developed at NASA Lewis Research Center, was used for the fuzzy logic analyses. Although both techniques provided estimates of the reliability of the IME and Discrete systems, probabilistic techniques emphasized uncertainty resulting from randomness in the system whereas fuzzy logic techniques emphasized uncertainty resulting from vagueness in the system. Because uncertainty can have both random and vague components, both techniques were found to be useful tools in the analysis of rocket engine system reliability.

\section{SUBJECT TERMS}

Fuzzy logic; Risk assessment; Reliability; Rocket propulsion

15. NUMBER OF PAGES

17. SECURITY CLASSIFICATION
OF REPORT
Unclassified

18. SECURITY CLASSIFICATION OF THIS PAGE Unclassified
19. SECURITY CLASSIFICATION OF ABSTRACT Unclassified 